\title{
PATIENT CENTERED CARE MODEL TO IMPROVE THE QUALITY AND SAFETY OF PATIENT CARE IN HOSPITAL: A SYSTEMATIC REVIEW
}

\author{
Ni Putu Sri Wahyuni, Ede Surya Darmawan \\ Masters Program in Hospital Administration, Faculty of Public Health, \\ Universitas Indonesia
}

\begin{abstract}
Background: Patient Centered Care (PCC) is a health care system focused on patients. This system has concept that places patients as subjects in each care provided. This study aimed to systematically review the PCC model to improve the quality and safety of patient care in hospital.

Subjects and Method: This was a systematic review conducted by searching articles in the period of 2010 to 2018, using PubMed, Google Scholar, and Scopus databases. The keywords were "Patient Centered Care", "quality", and "patient safety". The articles were reviewed by PRISMA flow diagram.

Results: Seven studies reported that PCC was carried out in the attitudes of respecting the dignity of patients and families; maintaining safety and comfort; allowing active family participation; providing information, communication, and education; providing the best services; and benefiting team collaboration. The core concept of PCC was to show patients as a unique individual, respecting their value and belief, and responding flexibly to patient's need and choice. The PCC approach was proven to improve patient status through improved communication, to foster a positive climate, and to encourage interaction between patients and service providers. Interaction was carried out on an ongoing basis that might improve communication so as to avoid unexpected things.

Conclusion: Patient Centered Care (PCC) increases the outcomes of health services and minimizes unexpected things.
\end{abstract}

Keywords: patient centered care, quality, and patient safety

\section{Correspondence:}

Ni Putu Sri Wahyuni. Masters Program in Hospital Administration, Faculty of Public Health, Universitas Indonesia, Depok, West Java. Email: wahyuni.upm@gmail.com. Mobile: +6281246976017 . 